\title{
Broadening the clinical spectrum for medical students towards primary care: a pre-post analysis of the effect of the implementation of a longitudinal clerkship in general practice
}

\author{
Roman Hari ${ }^{*}$, Michael Harris, Peter Frey and Sven Streit
}

\begin{abstract}
Background: Exposure to a broad spectrum of patient cases is a mainstay of undergraduate medical education. This study aimed to assess how many primary care-specific clinical pictures final-year medical students in traditional block rotations had encountered, and how this changed after a curricular change that included the implementation of a four-year longitudinal clerkship in primary care.

Methods: Final-year students before, and after, implementation of the clerkship were asked which of the clinical pictures most relevant to primary care they had seen. We compared the overall proportions of clinical pictures seen by the two cohorts.

Results: In the first cohort, 96 (66\%) students responded, and 94 (65\%) in the second. Before the curricular change, students had encountered a mean of 26.3 of the 34 primary care-specific clinical pictures (77.2\%). After implementation of the longitudinal clerkship, this increased by $1.1(4.2 \%, P=0.038)$. Among the eight clinical pictures seen the least by students in the first cohort, we found a significant increase in the proportion of students seeing polymalgia rheumatica, frozen shoulder, epicondylitis and Dupuytren's contracture after the clerkship's implementation.
\end{abstract}

Conclusion: The undergraduate longitudinal clerkship in primary care broadened the spectrum of clinical pictures seen by medical students, to include more clinical pictures commonly seen in primary care.

Keywords: Clinical teaching \& learning. Primary care. Curriculum evaluation. Undergraduate education

\section{Background}

Encountering a broad spectrum of patient cases in clinical work has long been a mainstay of undergraduate medical education [1]. The mixture of clinical conditions experienced in this setting is positively linked to positive learning experiences [2]. This is taken into account by the Swiss Catalogue of Learning Objectives for Undergraduate Medical Training (SCLO), a document that gives a list of the 1220 clinical pictures (the SCLO's term

\footnotetext{
* Correspondence: roman.hari@biham.unibe.ch

Institute of Primary Health Care Bern (BIHAM), University of Bern, Gesellschaftsstrasse 49, 3012 Bern, Switzerland
}

for diagnostic entities) that need to be encountered and mastered by medical students during their training [3].

Whilst originally the training of doctors had taken place in the community, the main place for medical learning during the twentieth century became the hospital [4], leading to a shift in clinical pictures experienced by medical students, and underrepresentation in their curriculum of those clinical pictures more commonly encountered in primary care.

In longitudinal clerkships, students spend an extended time in a clinical setting, where they have continuity of patient contact and care, assessment and supervision, and clinical and cultural learning $[5,6]$. These have been 
shown to have positive outcomes for students and patients, as well as supervising clinicians [7]. In recent decades, various undergraduate medical curricula have implemented longitudinal clerkships in general practice to broaden the educational spectrum for students [8]. This follows the 1988 Edinburgh Declaration of the World Federation for Medical Education, which advocated a substantial transfer of education from teaching hospitals to community settings [9]. Since then longitudinal clerkships have become recognised as representing credible and effective pedagogical alternatives to traditional block rotations in medical education [10]. In such clerkships, the majority of students have been found to be highly satisfied with their longitudinal placements [11], and students have done as well as, if not better than, their peers without such placements. In addition, in a longitudinal clerkship the continuity of contact with supervising doctors has been found to provide students with career mentorship and personal support, and students are more likely to report learning about chronic illness and communication skills, as well as receiving help in developing their clinical skills [12].

At the University of Bern in Switzerland, a curriculum reform has partially shifted the undergraduate clinical education setting from tertiary inpatients to communitybased sites, and a mandatory four-year longitudinal clerkship in general practice was established in 2007 [13]. Within this scheme, students are assigned a general practitioner (GP) who acts as their mentor throughout the first four years of their studies. In group practices, students are assigned to one mentor only, however cotutoring by other GPs in the same practice is common, especially to share interesting patient cases with the student or as substitute if the mentor GP is unavailable. If the assigned GP moves to a different practice, she or he is asked to supervise the student in their new practice. If the mentoring GP discontinues work, the practice is asked to continue supervision of the student. The model comprises eight half-days per year in the first three years, with a three-week primary care clerkship in the fourth year, all supervised by the same GP [13]. Before this curricular change there had been no mandatory training in general practice, and only $50 \%$ of students had chosen to take up an optional month-long clerkship in general practice in the final year of their training. The clerkship time in the hospital setting was reduced from 83 weeks to 49 weeks, including the removal of a threeweek course in clinical dermatology. This overall reduction in clinical experience gave students time to write a Master's thesis, as well as allowing more teaching time at the university campus, where lecture blocks in years 4-6 were expanded by 10 weeks to a total of 44 weeks.

The primary care longitudinal clerkships at the University of Bern differ considerably from some other longitudinal models. Whereas typical community placements in North America and Australia consist of at least 6 months spent continuously in a community setting $[14,15]$, our students only spend 27 days in primary care. This is mainly due to financial constraints. However, by distributing those days over 4 years, we have been able to establish sustained mentoring relationships between students and their assigned GPs.

While there is evidence that longitudinal clerkships in general practice have positive impacts on students' career choices [8] and their likelihood of achieving various intended learning outcomes [16], we could find no previous evidence that directly assessed how the introduction of longitudinal clerkships has affected the spectrum of clinical cases seen by medical students. We therefore planned a pre-post analysis to assess how many primary care-specific clinical pictures listed in the SCLO the final-year medical students in traditional block rotations had encountered, and how that changed after the implementation of a four-year longitudinal clerkship in general practice.

\section{Methods}

Study design

We performed a pre-post analysis of data from crosssectional surveys distributed to two groups of final year medical students, one cohort before and one after the implementation of a four-year longitudinal clerkship in general practice at the Medical Faculty of the University of Bern.

\section{Participants}

We invited medical students in 2009 (before implementation of the longitudinal clerkship) and 2012 (after implementation) to participate in a paper survey that was distributed and collected after a lecture at the end of their final (sixth) year of medical school. A three-year gap between cohorts was chosen to allow comparison between the last group that had not undergone the longitudinal clerkship in primary care, and the first group that had completed it. We chose physical distribution of the questionnaires in order to maximise the response rate, although some students may have been absent for these lectures. Data collection was anonymous, therefore, according to Swiss Law, no ethics committee approval was required.

\section{Study variables}

We developed a questionnaire for medical students in their final year to assess which of 34 clinical pictures from a pre-defined list they had seen in patient consultations at any time, and at any site, in their student years. The questionnaire also asked for the students' gender, career intentions ('GP, Specialist, Don't know yet'), and 
their rating of the attractiveness of general practice and specialism as careers using a Likert-Scale (from 1, 'Not attractive', to 5, 'Attractive'). As additional GP training was available to the medical students both before and after implementation of the longitudinal clerkship, we also asked whether they had taken that option up ('Yes/ No'). For an English translation of the questionnaire see Additional file 1 .

We used a three-step approach to select the SCLO clinical pictures of most relevance to general practice. First, we selected the 414 clinical pictures that were already marked as 'particularly relevant problems for General Practice and Outpatient Medicine' in the SCLO list. After this, we invited five GPs who were experienced in teaching medical students to classify each of those 414 items as "Yes, relevant for general practice" or "No, not relevant for general practice". Finally, in a face-toface meeting, the five GPs shared their ratings. Clinical pictures rated by all five GPs as being relevant were kept in the list, those rated by all as irrelevant were removed from the list. Where there was no initial unanimity, there was discussion until a consensus was reached as to whether or not the items were relevant to general practice, and thus whether they should be kept on, or removed from, the list. Following this process, the list comprised 34 clinical pictures; each of these fitted into six of the SCLO's thematic groups (Additional file 1).

\section{Statistical analysis}

We compared the characteristics of the two cohorts (before and after implementation of the longitudinal clerkship) using chi-squared tests for categorical data, and $t$ tests to compare continuous data. The proportions of clinical pictures seen by the cohorts were compared using a $t$ test. We used logistic mixed-effects models to derive odds ratios (OR) with $95 \%$ confidence intervals (CI) to compare the proportions before and after implementation of the clerkship for crude data, and also for a multivariate model with data adjusted for gender, career intention, attractiveness of GP and specialism, and uptake of additional GP training. A mixed-effects model was used to account for the multiple assessments per student. To assess how the biggest primary care-specific gaps in achievement of the learning objectives in the former curriculum were affected by the implementation of the new curriculum, we performed a sub-analysis of the quartile of primary care-specific clinical pictures least seen by the 2009 cohort. For this we used chisquared tests to make comparisons with the proportions seen by the 2012 cohort. We considered a $P$ value of 0.05 or less to be statistically significant. We performed all analyses with STATA version 14.2 (Stata Corp, College Station, TX, USA).

\section{Results}

In the 2009 cohort, 96 of 145 (66.2\%) medical students completed the questionnaire. In the 2012 cohort, 94 out of $145(65.8 \%)$ participated.

\section{Student characteristics}

Table 1 compares the student characteristics of the two cohorts. Both samples replied similarly in terms of their career intentions and their rating of the attractiveness of general practice and specialism as careers. However, significantly more medical students in the pre-longitudinal clerkship cohort reported that they had taken up the option of additional GP training $(49.0 \%$ in the 2009 cohort, $14.9 \%$ in the 2012 cohort, $P<0.001)$.

\section{Student experience of primary care-specific clinical pictures before and after the implementation of a longitudinal clerkship}

Students in the 2009 cohort had seen a mean of 26.3 of the 34 primary care-specific clinical pictures $(77.2 \%)$ during their training. Table 2 shows the mean number of clinical pictures seen by students in each of six thematic groups. After the implementation of the longitudinal clerkships in general practice, students saw a mean of 27.4 primary care-specific clinical pictures (80.7\%), an increase of $1.1(4.2 \%)$ over the previous cohort $(P=0.038)$.

Analysis of the clinical pictures in the six corresponding SCLO thematic groups shows a significant increase in the number of primary care-specific clinical pictures seen in musculo-skeletal disorders and internal medicine (non-musculo-skeletal) disorders. There was no significant difference in the number of clinical pictures seen by students in the surgical, psychiatric and otorhinolaryngological thematic groups. There was, however, a significant decrease the proportion of dermatological clinical pictures seen.

Table 1 Baseline Characteristics of the medical students before and after implementation of a longitudinal clerkship

\begin{tabular}{llll}
\hline Student characteristics & $\begin{array}{l}\text { Before } \\
n=96\end{array}$ & $\begin{array}{l}\text { After } \\
n=94\end{array}$ & $p$-value \\
\hline Female, n (\%) & $68(70.8)$ & $54(57.5)$ & 0.054 \\
Career intention, n (\%) & $14(14.6)$ & $17(18.5)$ & 0.41 \\
GP & $51(53.1)$ & $53(57.6)$ & \\
$\quad$ Specialist & $31(32.3)$ & $22(23.9)$ & \\
Don't know yet & & & \\
Career attractiveness rating ${ }^{\mathrm{a}}$, score (SD) & $3.4(1.0)$ & $3.4(1.0)$ & 0.57 \\
$\quad$ General Practice & $4.0(0.7)$ & $4.1(0.8)$ & 0.43 \\
Specialist & $47(49.0)$ & $14(14.9)$ & $<0.001$ \\
\hline
\end{tabular}

${ }^{\mathrm{a}}$ On a score from 1 (unattractive) to 5 (attractive) 
Table 2 Primary care-specific clinical pictures seen before and after implementation of a longitudinal clerkship

\begin{tabular}{|c|c|c|c|c|}
\hline $\begin{array}{l}\text { SCLO thematic } \\
\text { group }\end{array}$ & $\begin{array}{l}\text { Number of clinical } \\
\text { pictures in group }\end{array}$ & $\begin{array}{l}\text { Mean number of clinical pictures in group } \\
\text { seen by medical students in } 2009 \text { cohort (\%) }\end{array}$ & $\begin{array}{l}\text { Mean number of clinical pictures in group } \\
\text { seen by medical students in } 2012 \text { cohort (\%) }\end{array}$ & $P$-Value \\
\hline $\begin{array}{l}\text { Internal medicine, } \\
\text { musculo-skeletal }\end{array}$ & 5 & $2.6(51.0)$ & $3.5(70.6)$ & $<0.001$ \\
\hline $\begin{array}{l}\text { Internal medicine, } \\
\text { non-musculo-skeletal }\end{array}$ & 7 & $5.7(80.8)$ & $6.1(87.1)$ & 0.011 \\
\hline Surgery & 9 & $6.5(72.3)$ & $6.8(75.4)$ & 0.22 \\
\hline Psychiatry & 2 & $2.0(97.9)$ & $1.9(94.0)$ & 0.06 \\
\hline Dermatology & 5 & $4.4(88.5)$ & $4.0(79.6)$ & 0.002 \\
\hline Otorhinolaryngology & 6 & $5.2(85.9)$ & $5.2(86.0)$ & 0.98 \\
\hline Total & 34 & $26.3(77.2 \%)$ & $27.4(80.7)$ & 0.038 \\
\hline
\end{tabular}

Using the multivariate model, the odds ratio for these clinical pictures being seen by students was 1.11 in favour of the 2012 cohort (95\%CI 1.03 to 1.19 ).

\section{Changes in clinical pictures least seen by first cohort - Subgroup analysis}

The eight clinical pictures seen least by the 2009 cohort were seen by a mean of $51.8 \%$ those medical students (Table 3), and this increased to $67.6 \%$ in the 2009 cohort $(P=0.004)$. The biggest increases were in polymalgia rheumatica $(P<0.001)$, frozen shoulder $(P<0.001)$, epicondylitis $(P=0.005)$ and Dupuytren's contracture $(P=0.021)$ (Table 3$)$.

\section{Discussion}

Medical students saw only three-quarters of the 34 primary care-specific clinical pictures in the former, secondary care-centred undergraduate medical curriculum in Bern. After implementation of a longitudinal clerkship in general practice, we found a significant increase in the overall number of primary care-specific clinical pictures students reported that they had seen. This increase was particularly high for the subset of clinical pictures that had been least encountered by the 2009 cohort. Analysis of thematic groups showed that the largest increase in clinical pictures seen was that of the primary care-specific musculo-skeletal diseases, which may reflect the high prevalence of musculo-skeletal disorders in primary care.

The overall increase of primary care specific clinical pictures seen by students was 1.1 after the implementation of the new curriculum. This increase is small, however our intervention was itself relatively small. Further research is required to assess whether the effect size will increase in line with the size of the intervention, e.g. the number of days spent in practice. The other curricular changes may also have affected the outcomes, but although total clerkship time decreased from 83 to 49 weeks, there was still an overall positive impact of the curricular change on primary care specific clinical pictures seen by students. The reduction in the proportion of dermatological clinical pictures seen by students may have been related to the removal of the clinical dermatology block from the undergraduate course, for which the new clerkship in primary care could not fully compensate. Usually there are few or no few patient contacts when writing a Master's thesis, so we think it unlikely that this affected our primary endpoint. In the 2009 cohort, $49 \%$ of students reported that they had undergone

Table 3 Proportion of clinical pictures least frequently seen, before and after implementation of a longitudinal clerkship

\begin{tabular}{|c|c|c|c|c|}
\hline Clinical picture & $\begin{array}{l}\text { Number of students seeing picture } \\
\text { before implementation (\%) }\end{array}$ & $\begin{array}{l}\text { Number of students seeing picture } \\
\text { after implementation (\%) }\end{array}$ & Change in \% & $P$ value \\
\hline Polymyalgia rheumatica & $39(40.6)$ & $68(72.3)$ & $31.7 \%$ & $<0.001$ \\
\hline Frozen shoulder & $41(42.7)$ & $69(73.4)$ & $30.7 \%$ & $<0.001$ \\
\hline Torticollis & $48(50.0)$ & $51(54.3)$ & $4.3 \%$ & 0.56 \\
\hline Bites & $50(52.1)$ & 57 (60.6) & $8.6 \%$ & 0.24 \\
\hline Epicondylitis & $53(55.2)$ & $70(74.5)$ & $19.3 \%$ & 0.005 \\
\hline Dupuytren's contracture & $54(56.3)$ & $68(72.3)$ & $16.1 \%$ & 0.02 \\
\hline Ganglion of wrist & $56(58.3)$ & $60(63.8)$ & $5.5 \%$ & 0.44 \\
\hline Burns & $57(59.4)$ & $65(69.1)$ & $9.8 \%$ & 0.16 \\
\hline Mean & $49.8(51.8)$ & $63.5(67.6)$ & $15.7 \%$ & 0.004 \\
\hline
\end{tabular}


additional (optional) GP training; this rate decreased significantly to $14.9 \%$ in the 2012 cohort, most likely due to shortening of the elective period in year 6 and better coverage of primary care in the overall curriculum. This difference may have reduced the effect of the curricular change. The study had a response rate that was sufficiently high to reduce, but not eliminate, the risk of selection bias. While asking medical students about their past experience might have introduced recall bias, this bias would be expected to have affected both samples. Although considerably more medical students in the first cohort had done additional GP training, both this and factors relating to career choice were adjusted for in the multivariate model. A weakness of our study is that, as our study only looked at primary care-related clinical pictures, we have no evidence as to whether the increase in the proportion of these clinical pictures seen was accompanied by a change in the proportion of secondary care-related clinical pictures seen.

Whereas some studies [10, 17], like ours, have reported on students' own evaluations of their experience in longitudinal placements, other studies have used objective measures of skills. In a study using objective structured clinical examinations [18], students' early clinical skill development was at least as good for those having community-based longitudinal placements as for those in traditional placements. A study reporting on licensing examination results found that a longitudinal integrated clerkship (LIC) was equivalent to, and on standardised patient examinations was slightly superior to, that of traditional peers [19]. In another study, students in a community-based LIC achieved significantly higher grades than those who undertook the traditional rotation programme [20].

Furthermore, in a comparison between students participating in a longitudinal clerkship and students in block rotations, there was no difference in clerkship grade, and students received similar clinical evaluations in both systems [21]. That study did, however, identify that the average written examination score was lower for students in the longitudinal clerkship. Other studies have examined the effect of longitudinal curricula on more generic outcomes. Longitudinal curriculum students performed at least as well as traditional students in tests of content knowledge and skills, they were more likely to receive feedback and mentoring from experienced faculty [22], and they have had higher satisfaction with faculty teaching and feedback [19].

Students in longitudinal primary care programmes have greater confidence in their behavioural, verbal and interpersonal skills than their peers in traditional programmes [17]. They also report more continuity-of-care experiences, more confidence in their quality improvement skills, and scored higher on measures of perceived patient centeredness [23]. There is also evidence that patients value the long-term engagement of medical students in their primary health-care teams [24].

\section{Conclusion}

Our study provides evidence that longitudinal clerkships in general practice increases the number of GP-specific clinical pictures encountered by medical students compared to a traditional hospital-based curriculum, thereby broadening the spectrum of clinical pictures towards primary care in undergraduate medical education. Various aspects of the longitudinal clerkship design might have played an important role in this. Further research is required to ascertain which of these factors are the most effective in broadening the clinical spectrum of undergraduate medical education towards primary care.

\section{Additional file}

Additional file 1: Training-spectrum survey. English translation of the original questionnaire developed for this study. (DOCX $21 \mathrm{~kb}$ )

\section{Abbreviations \\ BIHAM: Institute of Primary Health Care, University of Bern, Bern, Switzerland; Cl: Confidence interval; GP: General practitioner; LIC: Longitudinal integrated clerkships; OR: Odds ratio; SCLO: Swiss Catalogue of Learning Objectives for Undergraduate Medical Training}

\section{Acknowledgements}

We thank the five GPS that participated by rating the SCLO items for relevance to general practice.

\section{Funding}

This work was not supported by a funding agency.

\section{Availability of data and materials}

The datasets used and/or analysed during the current study are available from the corresponding author on reasonable request.

\section{Authors' contributions}

PF developed the study protocol and supervised data collection. SS supervised the methodology and performed the statistical analysis. $\mathrm{MH}, \mathrm{RH}$ and PF assisted in the analysis and interpretation of data. $\mathrm{RH}$ drafted the first version of the manuscript. MH, PF and SS reviewed critically the manuscript. All authors read and approved the final manuscript.

\section{Authors' information}

Roman Hari is a Swiss general practitioner, clinical researcher and head of education at the institute of primary health care in Bern.

Michael Harris is a general practitioner in the UK. He has a special interest in medical education, both in Switzerland and the UK.

Peter Frey is the head of the student's office of the medical faculty of Bern. Sven Streit is a Swiss general practitioner, clinical researcher and head of career development with a special focus on promoting primary care on a national and international level.

\section{Ethics approval and consent to participate}

Verbal informed consent was obtained from all participants. The acquisition and use of data was in accordance with the Swiss Law on Data Protection [25]: No personally identifiable data were collected from the participants, that is, all personal data were recorded anonymously by the participants in order to avoid any inference as to the participants' identities. To avoid traceability, no record was kept of any personal data and its coding. This procedure is in accordance with the regulations of the Swiss Federal Act on 
Research involving Human Beings (Human Research Act, HRA, [26]). The HRA does not require ethics committee approval to collect and analyse anonymous non-medical data.

\section{Consent for publication}

Not applicable

\section{Competing interests}

The authors declare that they have no competing interests.

\section{Publisher's Note}

Springer Nature remains neutral with regard to jurisdictional claims in published maps and institutional affiliations.

Received: 28 June 2017 Accepted: 11 March 2018

Published online: 14 March 2018

\section{References}

1. de Jong J, Visser M, Van Dijk N, van der Vleuten C, Wieringa-de Waard M. A systematic review of the relationship between patient mix and learning in work-based clinical settings. A BEME systematic review: BEME guide no. 24 Med Teach. 2013;35(6):e1181-96.

2. de Jong J, Visser MR, Wieringa-de Waard M. Steering the patient mix of GP trainees: results of a randomized controlled intervention. Med Teach. 2013; 35(2):101-8.

3. Bloch $R$, Burgi $H$. The Swiss catalogue of learning objectives. Med Teach. 2002;24(2):144-50.

4. Thistlethwaite JE, Kidd MR, Hudson JN. General practice: a leading provider of medical student education in the 21st century? Med J Aust. 2007;187(2):124-8.

5. Ellaway R, Graves L, Berry S, Myhre D, Cummings BA, Konkin J. Twelve tips for designing and running longitudinal integrated clerkships. Med Teach. 2013:35(12):989-95.

6. Worley P, Couper I, Strasser R, Graves L, Cummings BA, Woodman R, Stagg P, Hirsh D. A typology of longitudinal integrated clerkships. Med Educ. 2016; 50(9):922-32.

7. Hudson J, Poncelet A, Weston K, Bushnell J, Farmer E. Longitudinal integrated clerkships. Med Teach. 2017;39(1):7-13.

8. Pfarrwaller E, Sommer J, Chung C, Maisonneuve H, Nendaz M, Junod Perron $\mathrm{N}$, Haller DM. Impact of interventions to increase the proportion of medical students choosing a primary care career: a systematic review. J Gen Intern Med. 2015;30(9):1349-58.

9. Education WFFM. The Edinburgh declaration. Med Educ. 1988;22:481-2.

10. Walters L, Greenhill J, Richards J, Ward H, Campbell N, Ash J, Schuwirth LW. Outcomes of longitudinal integrated clinical placements for students, clinicians and society. Med Educ. 2012;46(11):1028-41.

11. Thistlethwaite JE, Bartle E, Chong AA, Dick ML, King D, Mahoney S, Papinczak T, Tucker G. A review of longitudinal community and hospital placements in medical education: BEME guide no. 26. Med Teach. 2013; 35(8):e1340-64.

12. Wamsley MA, Dubowitz N, Kohli P, Cooke M, O'Brien BC. Continuity in a longitudinal out-patient attachment for year 3 medical students. Med Educ. 2009;43(9):895-906.

13. Schaufelberger M, Trachsel S, Rothenbühler A, Frey P. Eine obligatorische longitudinale Ausbildung von Studierenden in 530 Grundversorgerpraxen. GMS Z Med Ausbild. 2009;26(2):6.

14. Weston KM, Hudson JN. Clinical scholarship among preceptors supervising longitudinal integrated medical clerkships in regional and rural communities of practice. Aust J Rural Health. 2014:22(2):80-5.

15. Woloschuk W, Myhre D, Jackson W, McLaughlin K, Wright B. Comparing the performance in family medicine residencies of graduates from longitudinal integrated clerkships and rotation-based clerkships. Acad Med. 2014;89(2):296-300.

16. O'Donoghue S, McGrath D, Cullen W. How do longitudinal clerkships in general practice/primary care impact on student experience and career intention? A cross-sectional study of student experience. Educ Prim Care. 2015:26(3):166-75.

17. Verby JE. The Minnesota rural physician associate program for medical students. J Med Educ. 1988;63(6):427-37.

18. Carney PA, Ogrinc G, Harwood BG, Schiffman JS, Cochran N. The influence of teaching setting on medical students' clinical skills development: is the academic medical center the "gold standard"? Acad Med. 2005;80(12):1153-8.
19. Poncelet A, Bokser S, Calton B, Hauer KE, Kirsch H, Jones T, Lai CJ, Mazotti L, Shore W, Teherani A, et al. Development of a longitudinal integrated clerkship at an academic medical center. Med Educ Online. 2011;16: 10.3402/meo.v16i0.5939.

20. Mahoney S, Worley P, Parry H, Clarke S. Urban general practice and medical education: academic outcomes from a unique urban, longitudinal integrated community-based program. Aust Fam Physician. 2016;45(10):754-7.

21. Frattarelli LC, Kamemoto LE. Obstetrics and gynecology medical student outcomes: longitudinal multispecialty clerkship versus traditional block rotations. Am J Obstet Gynecol. 2004;191(5):1800-4.

22. Ogur B, Hirsh D, Krupat E, Bor D. The Harvard Medical School-Cambridge integrated clerkship: an innovative model of clinical education. Acad Med. 2007;82(4):397-404.

23. Henschen BL, Bierman JA, Wayne DB, Ryan ER, Thomas JX, Curry RH, Evans DB. Four-year educational and patient care outcomes of a team-based primary care longitudinal clerkship. Acad Med. 2015;90(11 Suppl):S43-9.

24. Hudson JN, Knight PJ, Weston KM. Patient perceptions of innovative longitudinal integrated clerkships based in regional, rural and remote primary care: a qualitative study. BMC Fam Pract. 2012;13:72.

25. Federal Act on Data Protection (FADP). https://www.admin.ch/opc/en/ classified-compilation/19920153/index.html. Accessed 26 Jan 2018.

26. Human Research Act (HRA). http://www.admin.ch/opc/en/classifiedcompilation/20121176/201401010000/810.305.pdf. Accessed 26 Jan 2018

\section{Submit your next manuscript to BioMed Central and we will help you at every step:}

- We accept pre-submission inquiries

- Our selector tool helps you to find the most relevant journal

- We provide round the clock customer support

- Convenient online submission

- Thorough peer review

- Inclusion in PubMed and all major indexing services

- Maximum visibility for your research

Submit your manuscript at www.biomedcentral.com/submit 